\title{
The basis of nonhost resistance for future genetic engineering to find out durable resistance in agricultural crops
}

\author{
Md. Shamim ${ }^{1}$, Ashutosh Singh ${ }^{2}$, Mayank Kaashyap ${ }^{3}$, R. P. Saxena ${ }^{1}$, Deepti Srivastava ${ }^{1}$, \\ Pramila Pandey ${ }^{1}$, N. A. Khan ${ }^{1}$ and K. N. Singh ${ }^{1 *}$ \\ ${ }^{1}$ Department of Plant Molecular Biology and Genetic Engineering, Dr. R. M. L. Institute of Plant Biodiversity and \\ Biotechnology, N. D. University of Agriculture and Technology, Kumarganj, Faizabad 224229 (U.P.) India. \\ ${ }^{2}$ Genetics Division, Indian Agricultural Research Institute, New Delhi, 110012 India. \\ ${ }^{3}$ International Crops Research Institute for the Semi-Arid Tropics (ICRISAT), Patancheru-502 324, (A. P.), India.
}

Accepted 27 July, 2013

\begin{abstract}
Plant disease resistance is one of the most desirable traits for agricultural production, especially in the present time of fear over food production and crop security. Disease plays an important role in crop production and quality of products. The one key factor of food security and production is plant disease resistance. Several resistance gene(s) are reported from the same host range to overcome against disease resistance. These resistance $(R)$ genes are not durable in many cases because of rapid changes in the pathogen population to overcome the resistance that they confer. For diagnosing such type of situation, continuous search of durable resistance sources from across the genera/species are desirable. Second type of resistance that is nonhost resistance has been described as inaccessibility. Nonhost resistance is regarded as a robust protection against pathogenic microorganisms because of its durability. The mechanisms of nonhost resistance could also be exploited to improve the resistance in a range of crop plants. Recently several components of nonhost resistance have been identified but such resistance is one of the least understood phenomenons in the area of plant microbe interaction. Molecular mechanism of nonhost resistance is not fully understood. Though, nonhost resistance will help biologist to engineer the plants for more durable resistance against important plant diseases. Therefore, non-host resistance seems to be one avenue under consideration for significant improvement of agriculture production in future.
\end{abstract}

Key words: resistance gene, hypersensitive response, leucine rich repeat.

\section{INTRODUCTION}

Plants are sessile organisms, incapable of feeling the possibly harmful microorganisms. Defense of plants against pathogen infections are broadly based on diverse strategies. Plants possess a range of constitutive or inducible resistance mechanisms to defend themselves against the particular pathogenic attack. For this, plants may have evolved mechanisms to perceive pathogen attacks and to translate that perception into an adaptive response. In contrast to animals which possess specialized cells for defense, each individual plant cell possess

*Corresponding author. E-mail: kapildeos@hotmail.com. Tel: +915270262123. Fax: +915270262123.

Abbreviations: HR, Hypersensitive response; Avr, Avirulence; NHR, nonhost resistance; TTSS, Type III secretion system. 
a preformed inducible defense capability for their protection. Host resistance is shown by a particular cultivar within a plant species that as a whole is normally susceptible to the pathogen. On the other hand, nonhost resistance is expressed by all members of a plant species to a particular pathogen. However, even susceptible plants are capable of reacting in a way that may slow down growth of the pathogen. The presence of such basal resistance was evidenced in Arabidopsis by the isolation of enhanced disease susceptibility mutants (Heath, 2000). Extensive studies on gene for gene resistance have made it possible to clone $>40$ Resistance $(R)$ genes from plants (Martin et al., 2003). Such single dominant $R$ genes can be transferred within closely related species to protect the more agronomically useful crop plants. Resistance conferred by single dominant $R$ gene is specific to a particular pathogen race that can express the corresponding avirulance gene(s). Pathogen avirulance genes can be easily mutated or eliminated, and hence protection conferred by $\mathrm{R}$ genes is not durable.

Drawing a discrete line between host and nonhost status is not always straight forward, since some plant and pathogen that is species combinations suggest marginal host or near-nonhost status, when only few accessions of a plant species are at most moderately susceptible to a heterologous pathogen (Niks, 1987). It is generally concluded that the majority of plants are immune to the majority of microbes with pathogenic potential against the pathogen those can infect two plant species in a habitat (Yun et al., 2003). Nonhost resistance (NHR) is displayed at the species level that is all cultivars of a plant are resistant to infection by all genotypes within a pathogen species. Though nonhost resistance still remains poorly understood, but some important progress has been made in the recent year. Studies on the genetics of plant NHR identified critical components mediating cross-species resistance (Heath, 2002).

Due to the durable immunity, the molecular mechanism of nonhost resistance in plants outside the host range of a particular pathogen has attracted much attention earlier, which exerts broad-spectrum activity against the different disease causing species. NHR, however, has proved difficult to characterize as a result of the absence of a tractable genetic system. It is thought to be genetically complex, involving the deployment of both constitutive and inducible defense responses, in combination with a host physiology that may be routinely incompatible with pathogenesis. The present review is focused on recent advances of nonhost resistance, its mechanism and components involved in nonhost resistance towards plant systems.

\section{BASIS OF HOST AND NONHOST RESISTANCE}

\section{Broad spectrum of host and non-host resistance}

Resistance to different diseases of plants has historically been classified into two major categories, (i) host and (ii) nonhost resistance. Host resistance to plant pathogen has been more thoroughly investigated, unlike non-host resistance, because it is genetically accessible (Gilbert and Webb, 2007). This general case is termed as host resistance, specific resistance, genotypic resistance, or cultivar resistance. Such resistance occurs when genetic polymorphism for susceptibility is observed in the same plant taxon, i.e., some genotypes show heritable resistance to a particular pathogen whereas other genotypes in the same gene pool are susceptible. In resistant individuals, the pathogen may or may not multiply to some extent, but spread of the pathogen through the plant is demonstrably restricted relative to susceptible hosts, and disease symptoms generally are either highly localized or are not evident. Host resistance, however, is usually restricted to a particular pathogen species and is commonly expressed against specific pathogen genotypes. In this case, plant specifically recognizes the invading pathogen and active defense responses are induced that lead to resistance. Elicitation of defense responses is mediated by the perception of pathogen signal molecules encoded by avirulence (Avr) genes only when the matching plant resistance $(R)$ gene is present, which results in an incompatible interaction between resistant host and avirulent pathogen. If the $R$ and/or Avr gene is absent or nonfunctional, the interaction between host (susceptible) and pathogen (virulent) is compatible. As opposed to the basal defense responses that often partially inhibit pathogens during colonization of the host plants, R-genemediated resistance involves a rapid and effective defense (Figure 1). Plant defends itself, as resistant (immune) reaction when it comes in contact with a pathogenic agent to which the plant is not a host (Figure 1). This is known as nonhost resistance and is the most common form of resistance (or defense from attack) in nature and unsuccessful plant/pathogen interactions represent nonhost resistance (Fraser, 1990). In nonhost resistance, all genotypes within a plant species show resistance or fail to be infected by a particular pathogen, specifically signifies the state where genetic polymorphism for susceptibility to a particular pathogen has not been identified in a host taxon. Although underlying mechanisms of nonhost resistance to pathogens are largely unknown and are likely as diverse for pathogen as they are for other classes of plant pathogens (Agrios, 1997). For example, mango tree will not be infected when the pathogens of tomato, of wheat, or of citrus trees come in contact to the above said plants, because the genetic makeup of mango tree is different to that of the host plant (tomato, wheat or citrus); are incompatible to each other and under that case due to that genetic constitution and needs specific reaction site for induction of disease/ specificity. Similarly, the fungus that causes Fusarium wilt on pigeon pea (Fusarium udum), does not infect pigeon pea, and so on unless it posses specificity for susceptible host. Understanding the ways by which infection fails to nonhost plants may be particularly important for break throughs in the development of plants with durable broad- 


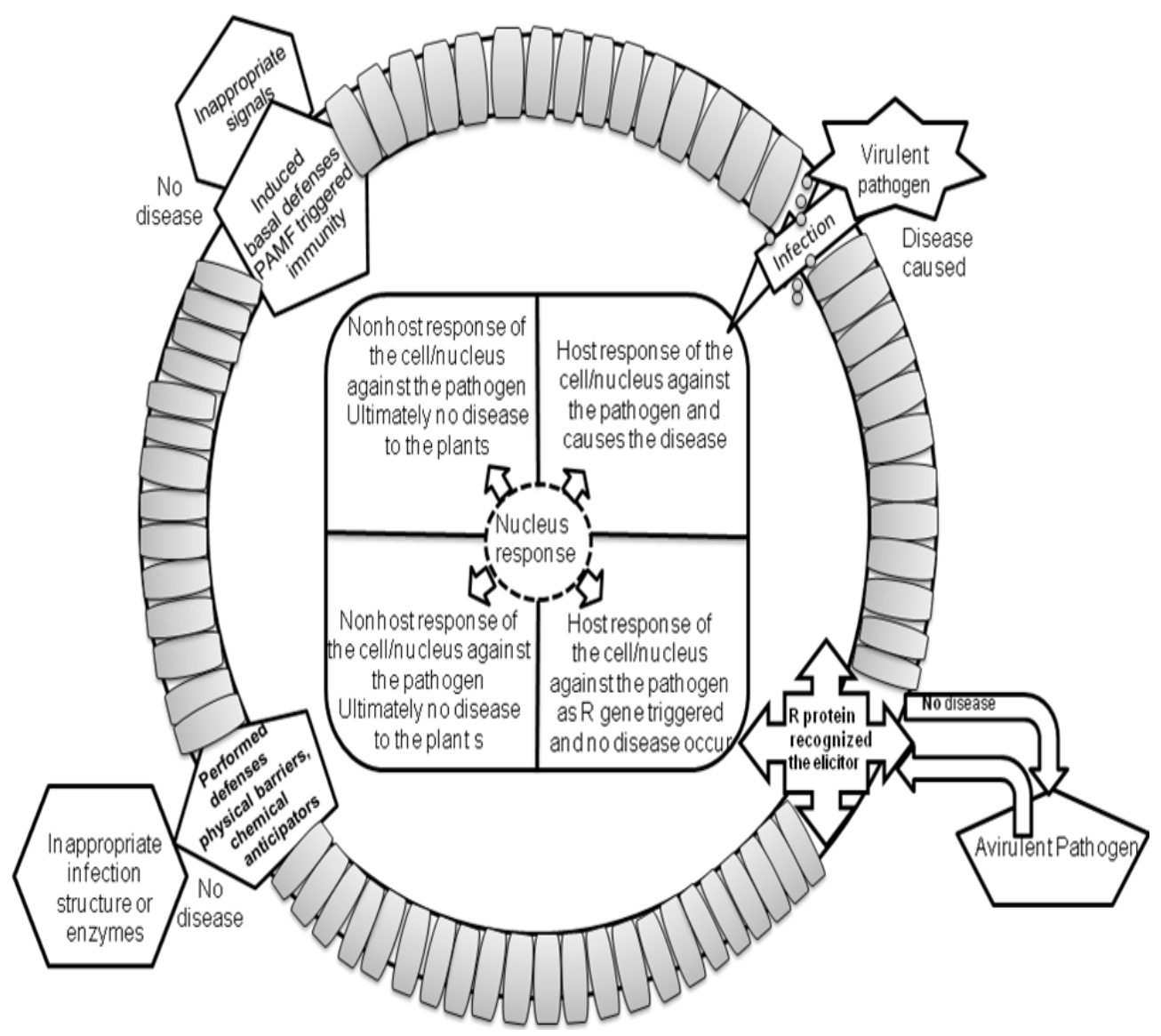

Figure 1. Interaction and disease development phenomenon in plant by host resistance and nonhost resistance

spectrum disease resistance.

\section{CLASSES OF NONHOST RESISTANCE}

The type of nonhost resistance depend how plants triggered in a resistance response and this depends on both the plants and pathogen species. Based on the observations recorded earlier, nonhost resistance against bacteria, fungi and oomycetes was classified into two types: type I and type II, however, it is still not clear that non-host resistance against viruses can be classified in the same manner (Mysore and Ryu, 2004) or a new classification have to be evolved for viruses. It is also reported that different plant species may show different resistance response by a single pathogen as both nonhost resistances type I and type II. This may be due to the fact that type I and type II are mainly resisted by the passive mechanism when essential host components are missing in the pathogen (Holub and Cooper, 2004). Tobacco and Arabidopsis mutant analysis also revealed that some of the signal transduction pathways of type II NHR might converge with host resistance pathways (Yun et al., 2003).

\section{Type I nonhost (non HR mediated) resistance}

Type I nonhost resistance is the most common type of non host resistance in plant system till date and this type of resistance does not produce any visible symptoms (necrosis or surface injury) on the infected plants. The pathogen will not be able to get pass the first or the second obstacle of the plant cell, and finally the multiplication and penetration of the pathogen into the plant in type I nonhost resistance will be completely arrested at the site of pathogen invasion. Though in this reaction the plant looks normal from their outer surface (without any visible symptoms), but inside the plant cell, several molecular changes might be happening. In some cases, nonhost resistance is not associated with induction of a hyper sensitive response, such that a nonhost plant species can show type I nonhost resistance against one pathogen species and type II resistance against another pathogen species. For example, Nicotiana benthamiana exhibits type I nonhost resistance against Xanthomonas campestris pv. campestris and type II nonhost resistance against Pseudomonas syringae pv. tomato. For example, $P$. syringae pv. phaseolicola triggers type I nonhost resistance in Arabidopsis and type II nonhost resistance 


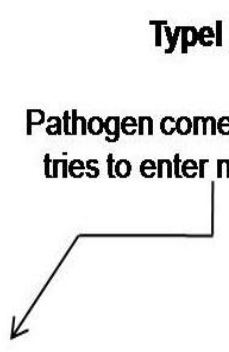

Ist barrier/(Passive defense mechanism) cell walls, antimicrobial compound and other secondary metabolites induced

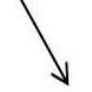

Typel nonhost resistance

$\downarrow$ tect on nonhost plants,

host tissue in search of

nutrition

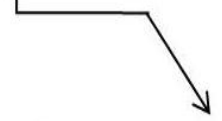

IInd obstacle, the pathogen

will faces the inducible plant defense responses (active defense mechanism)

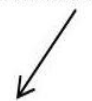

Plant recognize general elicitors from the pathogens in a nonspecific manner to activate defense response and also recognize pathogen surface molecules as pathogen-associated molecular patterns (PAMPs) to induce innate immunity

General response induced like, thickening, lignification of cell wall, accumulation of phenolics, production of saponins, ultimately production of PR gene<smiles>C[AlH]</smiles>

Pathogen will not able to past the $\mathrm{I}^{\text {st }}$ or $\mathrm{II}^{\text {nd }}$ obstacle, so multiplication not possible and penetration into the nonhost is

No disease appears (visuaually) though molecular changes inside the cell was continue along with infestation

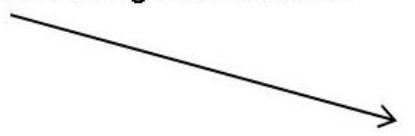

\section{Nonhost resistance}

response

The pathogen will face plant cellular defense surveillance

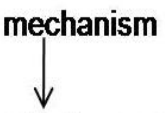

Ultimately plants systems recognize pathogen elicitor to counteract the pathogen in cytoplasm or at cell membrane

These resulting the HR response type of resistance

\section{Some pathogen} overcome early obstacles by producing detoxifying enzymes to overcome the toxic effect of preformed antimicrobial plant secondary metabolites<smiles>C=[V]C</smiles>

HR response by plants

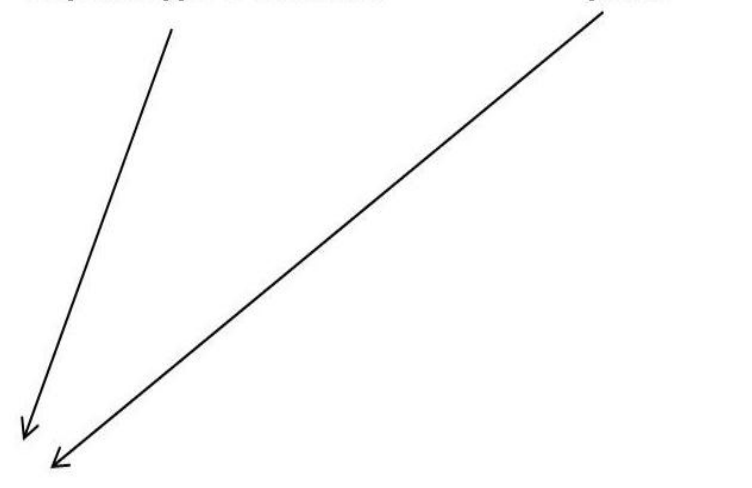

Figure 2. A. Resistance mechanism of the nonhost I, B. Resistance mechanism of the nonhost II to resist the pathogen.

in tobacco (Dawson and Hilf, 1992). In Figure 2A, the general model for the mechanism of type I (non-HRmediated) nonhost resistance is given.

\section{Type II nonhost (HR mediated) resistance}

Type II nonhost resistance is a more sophisticated plant defense mechanism than type I nonhost resistance and phenotypically similar like as an incompatible gene-forgene interaction. Unlike to type I nonhost resistance, type II nonhost resistance is always associated with rapid localized necrosis (HR). An elicitor(s) will be recognized by the plant surveillance system and a defense reaction leading to HR will be activated. This will prevent the further spread of the pathogen from the infected cell
(Figure 2B). Similarities were reported between nonhost as well as in gene for gene resistance responses but it is still not clear what mechanisms are involved in producing these resistance responses. It has been reported that some pathogens can conquer early obstacles by producing detoxifying enzymes to overcome the toxic effect of preformed antimicrobial plant secondary metabolites (Lu et al., 2004). In the second phase of the plants, when it faces the pathogen, then the plant internal cellular system goes to defense surveillance. After that the plants have evolved to recognize certain pathogen elicitors, either in the plant cytoplasm or at the plant cell membrane, a defense mechanism is triggered to hyper sensitive response. Such type of pathogen elicitors can be recognized by plants to activate defense responses known as avirulence (Avr) proteins. Avr proteins when not recognized 
by plants can enhance the virulence of pathogens (Osbourn, 1996). Once a pathogen can overcome preformed and general elicitor induced barriers, fungal and oomycete pathogens can directly penetrate a plant cell whereas most plant bacterial pathogens inject virulence and avirulence proteins into the plant cell through a hrp gene-encoded type III secretion system (TTSS). For fungal and oomycete pathogens, the extracellular proteins on the hyphae or secreted proteins serve as elicitors whereas the injected avirulence proteins serve as elicitors for bacterial pathogens (Shan et al., 2004).

\section{MECHANISM OF RESISTANCE AND EXAMPLE OF NONHOST RESISTANCE}

\section{Mechanism and examples of nonhost resistance}

In general, a pathogen lands on a nonhost plant, then it tries to enter the host tissue in search of nutrition for its biological activity. After landing, the pathogen will face plant barriers (known as passive defense mechanisms), the first barrier like cell walls, second antimicrobial compounds and other secondary metabolites (Hutcheson et al., 2001). Third barrier against the pathogen is the inducible plant defense responses (known as active defense mechanisms). After induction of the third barriers in plants, it recognizes general elicitors from pathogen population in a nonspecific manner to activate its defense machinery. In other way, plants can also recognize pathogen surface molecules referred as pathogen-associated molecular patterns (PAMPs), to induce innate immunity. PAMPs are shared among members of a pathogen group and are known to induce innate immunity in both plants and animals systems. Some of the plant defense responses that are induced because of general elicitors and PAMPs include cell wall thickening, cell wall lignification, and accumulation of phenolics, production of saponins, and production of phytoalexins, papilla formation and induction of pathogensis related genes (ThordalChristensen, 2006). Like the host systems, nonhost interactions with pathogens can also mount/ induced a battery of induced barriers against pathogen infection. Arabidopsis is a nonhost for $P$. syringae pv. phaseolicola and when infected with $P$. syringae pv. phaseolicola, it activates PR gene expression without any visible symptoms (Dawson and Hilf, 1992).

Specific resistance has been extensively studied in host pathosystems and typically follows Flor's gene-forgene model (Dixon, 2001), in which resistance is determined by the simultaneous expression of pathogen avirulence (Avr) gene and the corresponding plant resistance $(R)$ gene. Most contemporary models of non-host resistance evoke a complex overlay of specific resistance and nonspecific defense responses (Staskawicz et al., 1995). However, the extent to which the gene-for-gene model applies to non-host interactions remains unclear. A classical genetic approach to this problem is hampered by the absence of variation in plant resistance and pathogen virulence, as well as by sexual incompatibility between host and non-host plants. Specific resistance has been extensively studied in host pathosystems and typically follows Flor's gene-for-gene model. Resistance is determined by the simultaneous expression of pathogen avirulence (Avr) gene with the corresponding plant resistance gene, leading to the hypersensitive response (HR), a general defense response of plants that includes apoptotic cell death (Nurnberger and Brunner, 2002). The extent to which the gene-for-gene model can be expanded to non-host interactions remains unclear. However, in many pathosystems, non-host resistance can be explained by the occurrence of an arsenal of $R$ genes that recognize multiple or essential Avr genes (Dangl and Jones, 1998). Although historically, the above classifications have been quite stringent, plant pathologists have recently begun to appreciate major genetic and molecular intersections between the various types of plant immunity. For example, genes such as NPR1 and EDS1/ PAD4, which encode key components of salicylic acid mediated plant defense signaling, were found to be essential for various types of disease resistance (Kamoun, 2001). Likewise, global transcription profiling revealed similar sets of genes whose expression is altered during basal defense, $\mathrm{R}$ gene-triggered immunity and in non-host interactions (Lipka et al., 2005; Caldo et al., 2004). NB-LRR and PRR-triggered immunity contribute to nonhost resistance such that with increasing phylogenetic divergence time between two plant species, the relative effectiveness of PRR-triggered immunity increases whereas the relative contribution of NB-LRR protein-triggered immunity decreases (Caldo et al., 2004; Zimmerli et al., 2004). The other one mechanistic explanation for this could be that effectors from a given pathogen species fail to effectively suppress PRR-triggered immunity in nonhosts because their corresponding host cellular targets have diverged in the nonhost to an extent that impedes effective manipulation by the effector repertoire. Additionally, the continuous co-evolutionary arms race between host-adapted pathogens and their hosts appears to drive a more rapid evolution of NB-LRR loci compared to the rest of plant genomes (SchulzeLefert and Panstruga, 2011).

\section{IDENTIFICATION OF NONHOST RESISTANCE GENE(S) AND NEW ADVANCEMENT IN THROUGH MOLECULAR TOOLS}

\section{Identification and advancement in nonhost resistance through molecular tools}

Mutants of Arabidopsis ( $A$. thaliana) are used for the identification of several genes that contribute to nonhost resistance against the barley powdery mildew fungus Blumeria graminis f. sp. hordei. The study then hypothe- 
sized that the multilayered nonhost resistance was found in plants, with the plant cell wall being the first and rapid cell death the second line of defense. In wild-type plants, inappropriate pathogens to which Arabidopsis is a nonhost are usually stopped at the preinvasive stage of penetration. This penetration resistance is associated with the formation of large cell wall appositions (papillae) enriched in callose, lignin-like material, and hydrogen peroxide (Leister et al., 1998). Upon breaching of this first defense layer, pathogen growth is stopped by a hypersensitive reaction of attacked cells, which is associated with auto fluorescence and a hydrogen peroxide burst and which leads to cell death (Stein et al., 2006). Recently, it has been shown that genes of Arabidopsis identified to play an important role in nonhost resistance against powdery mildews also contribute to resistance against nonhost rust fungi such as Phakopsora pachyrhizi (Schweizer, 2007). Arabidopsis NahG plants have a defect in resistance to the non-host bacterial pathogen P. syringae pv. phaseolicola NPS3121 (Psp), suggesting that SA-mediated signaling is required for non-host resistance to this pathogen. In light of the phenotypic differences between NahG and SA-signaling mutants (Loehrer et al., 2008), further investigation of the role of SA signaling in nonhost resistance to Psp observed that resistance of Arabidopsis to Psp was affected only in NahG plants and not in other genotypes with defects in SA signaling (Lu et al., 2001). Therefore, nonhost resistance to Psp is independent of SA signaling. In the nonhost interactions of barley with inappropriate rust fungi, a better understanding of the genetic basis of nonhost resistance was achieved recently by accumulating susceptibility alleles in a series of consecutive crosses, which resulted in two barley lines with essentially full susceptibility to nonhost rusts (Wees and Glazebrook, 2003). It was concluded, therefore, that nonhost resistance, at least to rust fungi, might depend on a complex and functionally redundant set of genes in barley. Barley (Hordeum vulgare subsp. vulgare) has been reported to be a nonhost to the wheat powdery mildew fungus Blumeria graminis f. sp. tritici, the wheat leaf rust (Rust) fungus Puccinia triticina, and isolate CD180 (CD) from the genus Magnaporthe that is associated with the host Pennisetum species (Atienza et al., 2004).

Amaize Rgene recognizes a rice pathogen, Xanthomonas oryzae pv. oryzicola, which causes bacterial streak disease in rice. Although $X$. 0 . pv. oryzicola does not cause disease on maize, though identified $R \times 01$ gene, a maize plant gene, conditions a resistance reaction to a diverse collection of pathogenic strains of $X$. oryzae. pv. oryzicola. Surprisingly, $R \times 01$ also controls resistance to the unrelated pathogen Burkholderia andropogonis, which causes bacterial stripe of sorghum and maize. The same gene also controls resistance reactions to both host pathogens and nonhost pathogens of maize. Rxo1 has a nucleotide-binding site leucine-rich repeat structure, simi- similar to many previously identified $\mathrm{R}$ genes (Zellerhoff et al., 2006). Most importantly, Rxo1 functions after transfer as a transgene to rice, demonstrating the feasibility of nonhost $\mathrm{R}$ gene transfer between cereals and providing a valuable tool for controlling bacterial streak disease. The function of $R \times 01$ in rice demonstrates that an NBS-LRR type of $R$ gene can be effectively transferred between distantly related cereals. In similar experiments, maize Rp1 genes, which are also NBS-LRR genes, did not function in wheat and barley (Ramakrishna et al., 2002). Other NBS-LRR R genes also have a restricted taxonomic functionality (Zhao et al., 2005), although some aspects of their function can sometimes be detected after transfer between distantly related species (Tai et al., 1999). If other $R$ genes function in heterologous cereal backgrounds, it will have a significant impact on strategies to improve disease resistance in most crops. Considering that the NBS-LRR genes account for $>1 \%$ of genes in the rice genome (Frost et al., 2004) and the thousands of different species of grasses, this could provide a deep resource of $R$ genes to control different phytopathogens. In the case of Rxo1, the maize gene confers broad resistance to a diverse group of $X$. oryzae. pv. oryzicola strains in rice (Monosi et al., 2004), where no $\mathrm{R}$ genes for this disease are known in host species. Some of the identified nonhost specific genes have novel functions when compared with known host-specific resistance and defense-related genes, respectively, revealing the existence of separate signaling and effector components (Mysore and Ryu, 2004). Some insights were also gained on the nature of elicitors leading to host speciesspecificity of Magnaporthe grisea (Murakami et al., 2003) and $X$. oryzae (Sweigard et al., 1995) suggesting that in some cases major genes appear to control host specificity and are likely to be recognized by specific plant receptors, yet to be identified.

Molecular mechanisms underlying HR of rice to its bacterial pathogen $X O C$ is mediated by a nonhost maize $\mathrm{R}$ gene. Rxo1 were investigated using a microarray experiment and a pair of transgenic and non-transgenic rice lines. Rxo1 appeared to function in the very early step of the interaction between rice and Xoc, and could specifically activate large numbers of genes involved in signalling pathways leading to HR and some basal defensive pathways such as SA and ET pathways. In the former case, $R \times 01$ appeared to differ from the typical host $\mathrm{R}$ genes in that it could lead to HR without activating NDR1. In the later cases, Rxo1 was able to induce a unique group of set of WRKY transcription factor genes and a large set of genes encoding PPR proteins that share the same G-box in their promoter regions with possible functions in post transcriptional regulation. Some key genes that function in the downstream of Rxo1 were identified, including OsNPR1 and OsPR1. Results elucidated some interesting aspects on the molecular mechanism of the non-host resistance of rice mediated by Rxo1 and provided useful information to understand the evolution of 
plant resistance genes (Zhao et al., 2004; Zhou et al., 2010).

Progress has been made in the model plant Arabidopsis, to a better understanding of the genes and pathways underlying nonhost resistance. The molecular basis of nonhost resistance is of obvious interest due to its durability, and potential transfer of this resistance mechanism(s) by transgenic approach to crop plants that are hosts of a given pathogen species will give a tool to better resistance. Future, research to find additional nonhost resistance gene against the important pathogens requires inter discipline approaches of genomics, structural biology, advanced genomics and bioinformatics tools. Genomics approaches will contribute by identifying candidate nonhost gene(s) and their determination of the positive selection. Structural biology is essential to understand the mode of interaction and inhibition of the pathogen. Advanced proteomics includes not only the sensitive pull down array to identifying and interaction but also activity based protein based assay for the determination of pathogen and non-host interaction. The potential of finding additional non-host gene(s) for the important pathogens is tremendous for better disease resistance. For all given the clear action of mechanism of action of the non-host resistance may be the additional layers of manipulation of several plant species with the molecular battlefield to the non-host resistance.

\section{ACKNOWLEDGEMENTS}

We thank Dr. Dharmendra Kumar, Department of Plant Pathology N. D. University of Agriculture and Technology, Kumarganj, Faizabad, for excellent technical assistance. The first author also acknowledges the U.G.C., New Delhi, Govt. of India, for the support as MAKA fellowship.

\section{REFERENCES}

Agrios GN (1997). Plant Pathology, $5^{\text {th }}$ edition Elsevier-Academic Press, San Diego, CA. pp. 208.

Atienza SG, Jafary H, Niks RE (2004). Accumulation of genes for susceptibility to Rust fungi for which barley is nearly a nonhost results in two barley lines with extreme multiple susceptibility. Planta 220: 71-79.

Caldo RA, Nettleton D, Wise RP (2004). Interaction-dependent gene expression in Mla-specified response to barley powdery mildew. Plant Cell 16: 2514-2528.

Dangl J, Jones JD (1998). Affairs of the plant: colonization, intolerance, exploitation and co-operation in plant-microbe interactions. Curr. Opin. Plant Biol. 1: 285-287.

Dawson WO, Hilf ME (1992). Host-range determinants of plant viruses. Ann. Rev. Plant Physiol. Plant Mol. Biol. 43: 527-555.

Dixon RA (2001). Natural products and plant disease resistance. Nature 411: 843-847.

Fraser RSS (1990). The genetics of resistance to plant viruses. Ann. Rev. Phytopathol. 28: 179-200.

Frost D, Way H, Howles P, Luck J, Manners J, Hardham A, Finnegan J, Ellis $J$ (2004). Tobacco transgenic for the flax rust resistance gene $L$ expresses allele-specific activation of defense responses. Mol. Plant Microbe Interact. 17: 224-232.

Gilbert GS, Webb CO (2007). Phylogenetic signal in plant pathogenhost range. Proc. Natl. Acad. Sci. USA 104: 4979-4983.
Heath MC (2000). Hypersensitive response-related death. Plant Mol. Biol. 44: 321-334.

Heath MC (2002). Nonhost resistance in plants to microbial pathogens. In: Ezekowitz RAB, Hoffmann JA (eds) Infectious Disease: Innate Immunity, Humana Press, Totowa, NJ. pp. 47-57.

Holub EB, Cooper A (2004). Matrix, reinvention in plants: how genetics is unveiling secrets of non-host disease resistance. Trends Plant Sci. 9: 211-214.

Hutcheson SW, Bretz J, Sussan T, Jin S, Pak K (2001). The enhancer binding protein HrpR and HrpS interact to regulate hrp-encoded type III protein secretion in Pseudomonas syringae strains. J. Bacteriol. 183: 5589-5598.

Kamoun S (2001). Nonhost resistance to Phytophthora: Novel prospects for a classical problem. Curr. Opin. Plant Biol. 4: 295-300.

Leister D, Kurth J, Laurie DA, Yano M, Sasaki T, Devos Graner A, Schulze-Lefert P (1998). Rapid reorganization of resistance gene homologues in cereal genomes. Proc. Natl. Acad. Sci. USA, 95: 370375.

Lipka V, Dittgen J, Bednarek P, Bhat R, Wiermer M, Stein M, Landtag J, Brandt W, Rosahl S, Scheel D, Llorente F, Molina A, Parker J, Somerville S, Schulze-Lefert P (2005). Pre and post invasion defenses both contribute to nonhost resistance in Arabidopsis. Science 310: 1180-1183.

Loehrer M, Langenbach C, Goellner K, Conrath U, Schaffrath U (2008). Characterization of nonhost resistance of Arabidopsis to the Asian soybean Rust. Mol. Plant Microbe Interact. 21: 1421-1430.

Lu G, Jantasuriyarat C, Zhou B, Wang GL (2004). Isolation and characterization of novel defense response genes involved in compatible and incompatible interactions between rice and Magnaporthe grisea. Theor. Appl. Genet. 108: 525-534.

Lu M, Tang X, Zhou JM (2001). Arabidopsis NHO1 is required for general resistance against Pseudomonas bacteria. Plant Cell 13: 437-447.

Martin GB, Bogdanove AJ, Sessa G (2003). Understanding the functions of plant disease resistance proteins. Ann. Plant Biol. 54: 23-61.

Monosi B, Wisser RJ, Pennill L, Hulbert SH (2004). Full-genome analysis of resistance gene homologues in rice. Theor. Appl. Genet. 109: 434-447.

Murakami J Tomita R Kataoka T Nakayashiki H Tosa Y, Mayama S (2003). Analysis of host species specificity of Magnaporthe grisea toward foxtail millet using a genetic cross between isolates from wheat and foxtail millet. Phytopathology 93: 42-45.

Mysore KS, Ryu CM (2004). Nonhost resistance: How much do we know? Trends Plant Sci. 9: 97-104.

Niks RE (1987). Nonhost plant-species as donors for resistance to pathogens with narrow host range 1. Determination of nonhost status. Euphytica 36: 841-852.

Nurnberger T, Brunner F (2002). Innate immunity in plants and animals: emerging parallels between the recognition of general elicitors and pathogen-associated molecular patterns. Curr. Opin. Plant Biol. 5: 318-324.

Osbourn AE (1996). Preformed antimicrobial compounds and plant defense against fungal attack. Plant Cell 8: 1821-1831.

Ramakrishna W, Emberton J, SanMiguel P, Ogden M, Llaca V, Messing $J$, Jeffrey LB (2002). Comparative sequence analysis of the sorghum Rph region and the maize Rp1 resistance gene complex. Plant Physiol. 130: 1728-1738.

Schulze-Lefert P, Panstruga RA (2011). A molecular evolutionary concept connecting nonhost resistance, pathogen host range, and pathogen speciation. Trends Plant Sci. 16(3):117-125.

Schweizer P (2007). Nonhost resistance of plants to powdery mildew: new opportunities to unravel the mystery. Physiol. Mol. Plant Pathol. 70: 3-7.

Shan L, He P, Zhou JM, Tang X (2000). A cluster of mutations disrupt the avirulence but not the virulence function of Avr Pto. Mol. Plant. Microb. Interact. 13: 592-598.

Staskawicz BJ, Ausubel FM, Baker BJ, Ellis JG, Jones JDG (1995). Molecular genetics of plant disease resistance. Science 268: 661667.

Stein M, Dittgen J, Sanchez-Rodriguez C, Hou BH, Molina A, SchulzeLefert P, Lipka V, Somerville S (2006). Arabidopsis PEN3/PDR8, an 
ATP binding cassette transporter, contributes to nonhost resistance to inappropriate pathogens that enter by direct penetration. Plant Cell 18: 731-746.

Sweigard JA, Carroll AM, Kang S, Farrall L, Chumley FG, Valent B (1995). Identification, cloning, and characterization of PWL2, a gene for host species specificity in the rice blast fungus. Plant Cell 7: 12211233.

Tai TH, Dahlbeck D, Clark ET, Gajiwala P, Pasion R, Whalen MC, Stall RE, Staskawicz BJ (1999). Expression of the Bs2 pepper gene confers resistance to bacterial spot disease in tomato. Proc. Natl. Acad. Sci. USA 96: 14153-14158.

Thordal-Christensen H (2003). Fresh insights into processes of nonhost resistance. Curr. Opin. Plant Biol. 6: 351-357.

Wees SCM, Glazebrook J (2003). Loss of non-host resistance of Arabidopsis NahG to Pseudomonas syringae pv. phaseolicola is due to degradation products of salicylic acid. Plant J. 33: 733-744.

Yun BW, Atkinson HA, Gaborit C, Greenland A, Rread ND, Palla JA, Loake GJ (2003). Loss of actin cytoskeleton function and EDS1 activity, in combination, severely compromises non-host resistance in Arabidopsis against wheat powdery mildew. Plant J. 34: 768-777.
Zellerhoff N, Jarosch B, Groenewald JZ (2006). Nonhost resistance of barley is successfully manifested against Magnaporthe grisea and a closely related Pennisetum-infecting lineage but is overcome by Magnaporthe oryzae. Mol. Plant Microbe Interact. 19: 1014-1022.

Zhao B, Ardales EY, Raymundo A, Bai J, Trick HN, Leach JE, Hulbert $\mathrm{SH}$ (2004). The avrRxo1 gene from the rice pathogen Xanthomonas oryzae pv. oryzicola confers a nonhost defense reaction on maize with resistance gene Rxo1. Mol. Plant Microbe Interact. 17: 771-779.

Zhao B, Lin X, Poland J, Trick H, Leach J, Hulbert S (2005). A maize resistance gene functions against bacterial streak disease in rice. Proc. Natl. Acad. Sci. USA 102(43): 15383-15388.

Zhou YL, Xu MR, Zhao MF, Xie WX, Zhu HL, Fu BY, Li ZK (2010). Genome-wide gene responses in a transgenic rice line carrying the maize resistance gene $R \times 01$ to the rice bacterial streak pathogen, Xanthomonas oryzae pv. oryzicola. BMC Genomics 11: 78.

Zimmerli L, Stein M, Lipka V, Schulze-Lefert P, Somerville (2004). Host and non-host pathogens elicit different jasmonate/ethylene responses in Arabidopsis. Plant J. 40: 633-646. 